\title{
Study of the dielectric parameters of aluminium ore bauxite of Mainpat area of Chhattisgarh at X-band frequency
}

\author{
S K SRIVASTAVA $^{1}$ and B R VISHWAKARAMA ${ }^{2}$ \\ ${ }^{1}$ Department of Physics, Govt, Post-Graduate College, Ambikapur 497 001, India \\ ${ }^{2}$ Department of Electronics Engineering, Institute of Technology, Banaras Hindu \\ University, Varanasi 221 005, India \\ e-mail: sk_srivastava@yahoo.com
}

MS received 6 October 2001; revised 24 May 2002

\begin{abstract}
A simple method for measuring the dielectric parameter of materials in the form of powders at microwave frequencies is suggested. Measurement of the permittivity $\varepsilon^{\prime}$ and $\varepsilon^{\prime \prime}$ at $9.967 \mathrm{GHz}$ on powder samples of the aluminum ore bauxite gives interesting results. It is found that $\varepsilon^{\prime}$ and $\varepsilon^{\prime \prime}$ increases with packing densities $(\delta)$. Further $\varepsilon^{\prime}$ and $\varepsilon^{\prime \prime}$ also depend upon the percentage of $\mathrm{Al}_{2} \mathrm{O}_{3}$. These results show that the values of $\varepsilon^{\prime}$ and $\varepsilon^{\prime \prime}$ can be used to set certain basic values for minability of the ore for a particular sample. Conductivities $(\sigma)$ and relaxation $(\tau)$ are also calculated in the present studies.
\end{abstract}

Keywords. Dielectric parameters; aluminium ore; packing density; minability of ore.

\section{Introduction}

Dielectric properties of solids in the form of powders may be useful in understanding the structural behaviour of particles in an alternating field. These studies may also be used to formulate models for predicting the dielectric properties of packed beds. Many solid electrolytes are used as the major component in the preparation of binary and ternary compounds. The dielectric constant and the conductivity of such solids in the particulate form are of importance for the behavioural study of these compounds. Powder compacts have acceptibility in technological work and such compacts are easy to fabricate. Particulate beds are finding applications in heavy electrical industry and the dielectric parameters of such beds are gaining importance these days. There is need for an accurate and convenient technique to measure the dielectric properties of solids in the form of powders. With this view in mind we are presenting here an accurate technique for measuring the dielectric parameters of solids in the form of powder. Yadav \& Gandhi (1992) and Gandhi et al (1993) have found that dielectric parameters of powders at microwave frequencies are distinctly changed in the presence of conducting impurities. These results suggest that dielectric properties of powdered ores at microwave frequencies may be useful in providing important information about the type of metals and its concentration present in the sample employed. Consequently it may be possible to evaluate the worth of a particular ore for mining purposes. Materials used to test the 
performance of the proposed method are from the Mainpat area. An attempt has been made to measure the dielectric constant of powder sample at spot frequency $9.967 \mathrm{GHz}$ and the results obtained are discussed.

\section{Geographical situation of Mainpat}

This area is situated in Surguja District of Chhattisgarh. The Bharat Aluminium Company (BALCO), Korba has established its branch office there for extraction of aluminium from its ores. The average temperatures in Winter and Summer are $11-15^{\circ} \mathrm{C}$ and $22-25^{\circ} \mathrm{C}$ respectively. Its lattitute and longitude vary from $22^{\circ} 45^{\prime}-22^{\circ} 53^{\prime}$ to $83^{\circ} 18^{\prime}-83^{\circ} 25^{\prime}$. It is spread over $29 \mathrm{~km}$ in length and $12 \mathrm{~km}$ breadth. Its peak height is $1152 \mathrm{~m}$ and height from sea shore is $990 \mathrm{~m}$. It is the main tourist spot of Chhattisgarh.

\section{Materials and method}

When a rectangular wave guide filled with a dielectric material of complex permittivity $\varepsilon^{*} *$ is excited in the $\mathrm{TE}_{m, n}$ or $\mathrm{TM}_{m, n}$ mode, the propagation constant $\gamma_{d}$ can be written as (Altshuler 1981)

$$
\gamma_{d}=\alpha_{d}+j \beta_{d}=j 2 \pi / \lambda_{0}\left[\varepsilon *-\left(\lambda_{0} / \lambda_{c}\right)^{2}\right]^{(1 / 2)},
$$

where $\alpha_{d}$ is the attenuation introduced by the unit length of the materials (in Nepers $/ \mathrm{m}$ ), $\beta_{d}$ is the phase shift introduced by the unit length of the dielectric materials (in radian $/ \mathrm{m}$ ), $\lambda_{0}$ is the wavelength in free space and $\lambda_{c}$ is the cutoff wavelength of the wave guide. Substituting $\varepsilon *=\varepsilon^{\prime}-j \varepsilon^{\prime \prime}$ in (1) and separating real and imaginary parts, we get

$$
\begin{aligned}
& \varepsilon^{\prime}=\left(\lambda_{0} / \lambda_{c}\right)^{2}+\left(\lambda_{0} / \lambda_{d}\right)^{2}\left[1-\left(\alpha_{d} / \beta_{d}\right)^{2}\right], \\
& \varepsilon^{\prime \prime}=2\left(\lambda_{0} / \lambda_{d}\right)^{2}\left(\alpha_{d} / \beta_{d}\right) .
\end{aligned}
$$

For low loss materials (2) and (3) reduce to

$$
\begin{aligned}
\varepsilon^{\prime} & =\left(\lambda_{0} / \lambda_{c}\right)^{2}+\left(\lambda_{0} / \lambda_{d}\right)^{2}, \\
\varepsilon^{\prime \prime} & =\pi^{-1}\left(\lambda_{0} / \lambda_{d}\right)^{2} \alpha_{d} \lambda_{d} .
\end{aligned}
$$

Equations (4) and (5) can now be employed to obtain the values of $\varepsilon^{\prime}$ and $\varepsilon^{\prime \prime}$. The main quantities to be measured experimentally are $\alpha_{d}$ and $\lambda_{d}$ for the samples for which the values of $\varepsilon^{\prime}$ and $\varepsilon^{\prime \prime}$ are to be obtained.

Microwave power is obtained from a microwave source and is allowed to form standing waves in the slotted wave-guide section after being reflected from the short-circuiting plunger in the dielectric cell. The probe in the slotted wave-guide is accurately adjusted to the minimum. Now if a small quantity of powder is introduced so that it occupies a height $(h)$ of the cell and the plunger is brought over it, the minimum will shift either towards the receiver and when $h>\lambda_{d} / 4>\lambda_{d} / 2$ the minimum shifts toward the generators. If $h_{1}$ and $h_{2}$ are two heights of the powder in the cell for which equal shift in the minimium is towards the receiver and generators respectively, then

$$
\begin{aligned}
& \left(2 \pi / \lambda_{d}\right) h_{1}=\left(2 \pi / \lambda_{g}\right) x, \\
& \left(2 \pi / \lambda_{d}\right) h_{2}=\left[\left(\pi-\left(2 \pi / \lambda_{g}\right) x\right)\right] .
\end{aligned}
$$


Combining (6) and (7), we get

$$
\lambda_{d}=2\left(h_{1}+h_{2}\right) .
$$

To obtain $\alpha_{d}$, the plunger is kept at the bottom of the cell, i.e with no powder in it and the probe is located at the maximum. The reading $X_{1}$ of the indicator is noted. Powder is added slowly in to the cell. If for a height $h$ of the powder column, the deflection is shown by indicator is $X_{2}$, then $\alpha_{d}$ can be calculated (Yadav et al 1992) as

$$
\alpha_{d}=(2.303 / 2 h) \log \left(X_{1}^{1 / 2} / 2 X_{2}^{1 / 2}-X_{1}^{1 / 2}\right) .
$$

The attenuation factor and phase constant in a powder sample can also be calculated using (Von Hippel 1961)

$$
\alpha=\left(\lambda \omega^{2} / 4 \pi\right)\left(\varepsilon^{\prime} \mu^{\prime \prime}+\varepsilon^{\prime} \mu^{\prime \prime}\right),
$$

and phase factor

$$
\beta=2 \pi / \lambda=\omega\left(\varepsilon^{\prime} \mu^{\prime \prime}-\varepsilon^{\prime} \mu^{\prime \prime}\right) / 2\left\{1+\left\{\left(\varepsilon^{\prime} \mu^{\prime \prime}+\varepsilon^{\prime \prime} \mu^{\prime}\right) /\left(\varepsilon^{\prime} \mu^{\prime}+\varepsilon^{\prime \prime} \mu^{\prime \prime}\right)\right\}^{1 / 2}\right\}^{2}
$$

for materials with negligible magnetic loss $\left(\mu^{\prime \prime}=0\right)$ we obtain from (11) for wavelength the simplified expression

$$
\lambda=1 / \nu\left[1 / 2 \varepsilon^{\prime} \mu^{\prime}\left\{1+\left(1+\tan ^{2} \delta\right)^{1 / 2}\right\}\right]^{1 / 4} .
$$

If in addition the permeability is that of vacuum $\left(\mu^{\prime}=\mu_{0}\right)$ we may write for index of refraction

$$
\eta=\lambda_{0} / \lambda=\left[1 / 2 \kappa^{\prime}\left\{1+\left(1+\tan ^{2} \delta\right)^{1 / 2}\right\}\right]^{1 / 2} .
$$

Similarly attenuation factor becomes

$$
\alpha=2 \pi / \lambda_{0}\left[1 / 2 \kappa^{\prime}\left\{-1+\left(1+\tan ^{2} \delta\right)^{1 / 2}\right\}\right]^{1 / 2},
$$

where $\kappa^{\prime}=\varepsilon^{\prime} / \varepsilon_{0}$ is specific dielectric constant.

The index of absorption is represented as

$$
k=\alpha / \beta=\left[\left\{\left(1+\tan ^{2} \delta\right)^{1 / 2}-1\right\} /\left\{\left(1+\tan ^{2} \delta\right)^{1 / 2}+1\right\}\right]^{1 / 4},
$$

where $\tan \delta=\varepsilon^{\prime \prime} / \varepsilon^{\prime}$.

The materials used in the present studies were obtained from Bharat Aluminium Company (BALCO), Mainpat in powder form. The samples contain inorganic constituents such as $\mathrm{Fe}_{2} \mathrm{O}_{3}, \mathrm{TiO}_{2}, \mathrm{SiO}_{2}, \mathrm{Al}_{2} \mathrm{O}_{3}$ determined by the titration method as is given in table 1 . Experimental values of dielectric constant $\left(\varepsilon^{\prime}\right)$ and loss $\left(\varepsilon^{\prime \prime}\right)$, and conductivity $(\sigma)$, and relaxation time $(\tau)$ are listed in table 2 .

Table 1. Composition of samples of bauxite.

\begin{tabular}{lccccc}
\hline $\begin{array}{l}\text { Sample } \\
\text { No. }\end{array}$ & $\begin{array}{c}\mathrm{LoI} \\
(\%)\end{array}$ & $\begin{array}{c}\mathrm{Fe}_{2} \mathrm{O}_{3} \\
(\%)\end{array}$ & $\begin{array}{c}\mathrm{TiO}_{2} \\
(\%)\end{array}$ & $\begin{array}{c}\mathrm{SiO}_{2} \\
(\%)\end{array}$ & $\begin{array}{c}\mathrm{Al}_{2} \mathrm{O}_{3} \\
(\%)\end{array}$ \\
\hline 1 & 17.44 & $30 \cdot 20$ & 8.00 & 9.50 & 33.66 \\
2 & 22.57 & $12 \cdot 80$ & 8.80 & 6.79 & 48.45 \\
3 & 23.95 & $12 \cdot 10$ & 10.40 & 3.85 & 48.96 \\
4 & 24.06 & $10 \cdot 80$ & 12.00 & 2.72 & 49.47 \\
5 & 23.03 & $12 \cdot 80$ & 8.80 & 2.79 & 52.02 \\
6 & 25.81 & 7.90 & 10.80 & 2.35 & 52.33 \\
\hline
\end{tabular}


Table 2. Dielectric parameter, conductivity and loss tangent as functions of packing fraction and grain size.

\begin{tabular}{lcccccrcc}
\hline $\begin{array}{l}\text { Sample } \\
\text { No. }\end{array}$ & $\begin{array}{c}\text { Grain } \\
\text { size }(\mu)\end{array}$ & $\begin{array}{c}\text { Packing } \\
\text { fraction }\end{array}$ & $\varepsilon^{\prime}$ & $\varepsilon^{\prime \prime}$ & $\sigma$ & $\begin{array}{c}\tau \\
\left(\times 10^{-4}\right)\end{array}$ & $\begin{array}{c}\tan \delta \\
\left(\times 10^{-13}\right)\end{array}$ & $k$ \\
\hline 1 & $799-900$ & 0.313 & 7.132 & 0.431 & 2.38 & 9.65 & 0.0604 & 0.1732 \\
2 & $413-600$ & 0.413 & 8.231 & 0.573 & 3.17 & $11 \cdot 12$ & 0.0697 & 0.1865 \\
3 & $281-300$ & 0.415 & 9.431 & 0.987 & 5.36 & 16.71 & 0.1046 & 0.2285 \\
4 & $130-180$ & 0.443 & 9.987 & 1.512 & 8.37 & 34.18 & 0.1153 & 0.2400 \\
5 & $90-160$ & 0.453 & 10.381 & 2.121 & 11.75 & 32.64 & 0.2043 & 0.3487 \\
6 & $52-75$ & 0.460 & 11.281 & 3.312 & 18.35 & 46.90 & 0.2935 & 0.3842 \\
\hline
\end{tabular}

\section{Results and discussion}

Table 1 lists and values of permittivity $\left(\varepsilon^{\prime}\right)$, loss factor $\left(\varepsilon^{\prime \prime}\right)$, conductivity $(\sigma)$, relaxation time $(\tau)$ along with values of packing density, grain size (micron), and inorganic constituents used in the present studies. The value of $\sigma$ is obtained from the relation,

$$
\sigma=\omega \varepsilon_{0} \varepsilon^{\prime \prime}
$$

where $\omega$ is angular frequency of measurement and $\varepsilon_{0}$ is the permittivity of vacuum whose value is $8.854 \times 10^{-12} \mathrm{farad} / \mathrm{m}$.

Microwave data can be employed to determine the relaxation $(\tau)$ time using the relation

$$
\tau=\varepsilon^{\prime \prime} / \omega \varepsilon^{\prime}
$$

With the present results, the relaxation time in the samples vary with increasing values of $\delta$ from $9.65 \times 10^{-13} \mathrm{~s}$ to $46.90 \times 10^{-13} \mathrm{~s}$ respectively. These results are comparable to the values of $10^{-13} \mathrm{~s}$ as reported by Gandhi et al (1993) and Dube (1984) for Cu and silicon respectively. The rise in the relaxation time with increasing values of packing fraction $(f)$ is due to increasing hindrance to the process of polarization. Dielectric constants at different concentrations, conductivities and indexes of absorption are measured at different frequencies $(9.423 \mathrm{GHz}, 9.967 \mathrm{GHz}, 10.45 \mathrm{GHz})$ with respect to packing fraction of the powder form of sample. The results obtained are plotted in figures $1,2,3$ and 4 .

Figure 1 shows the variation of dielectric constant $\varepsilon^{\prime}, \varepsilon^{\prime \prime}$ with packing fraction $(f)$ for powder sample at different frequencies $9.423 \mathrm{GHz}, 9.967 \mathrm{GHz}, 10.45 \mathrm{GHz}$. It is found that the values of $\varepsilon^{\prime}, \varepsilon^{\prime \prime}$ increase with increasing value of packing fraction. This is to be expected because with higher values of packing fraction the inter-particles hindrance to dipolar motion increases giving rise to the higher values of $\varepsilon^{\prime}, \varepsilon^{\prime \prime}$ and $\sigma$ and this is similar to the values obtained by Yadav \& Gandhi (1992).

Figure 2 shows the variation of conductivity of powder sample with packing fraction at different frequencies $9.423,9.967$ and $10.45 \mathrm{GHz}$. It is found that conductivity increases with packing fraction and frequency. Samples having greater packing density possess higher conductivities.

Figure 3 shows the variation of index of absorption of microwave power with packing fraction at different frequencies $9.423,9.967$ and $10.45 \mathrm{GHz}$. It is found that index of absorption increases with packing fraction and frequency. Absorption of microwaves is greater in the sample having higher packing density. 


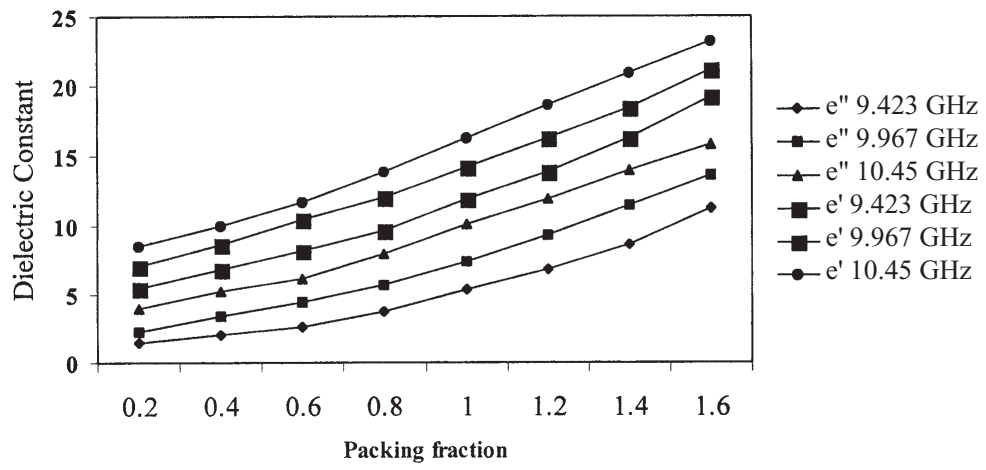

Figure 1. Variation of dielectric constant with packing fraction $(f)$ for powder samples at different frequencies $(9.423,9.967$ and $10.45 \mathrm{GHz})$.

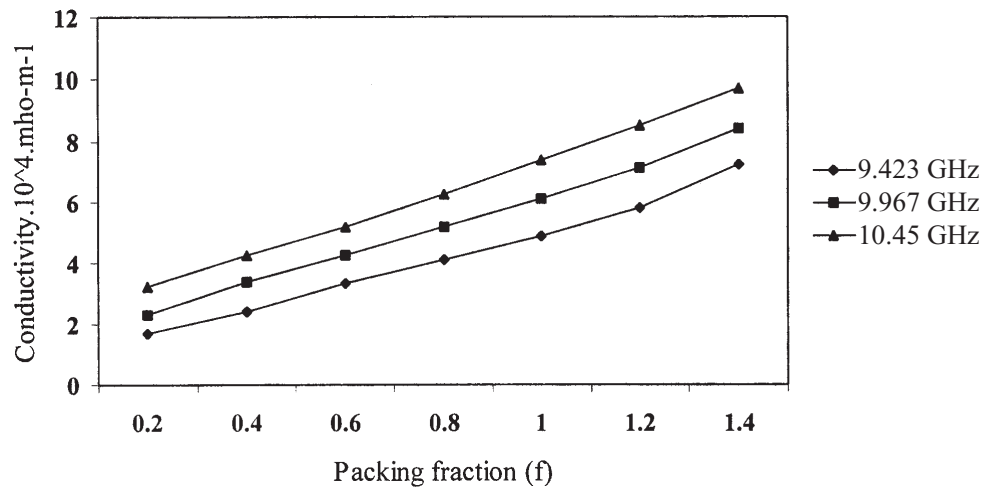

Figure 2. Variation of conductivity with packing fraction $(f)$ for powder samples at different frequencies $(9.423,9.967$ and $10.45 \mathrm{GHz})$.

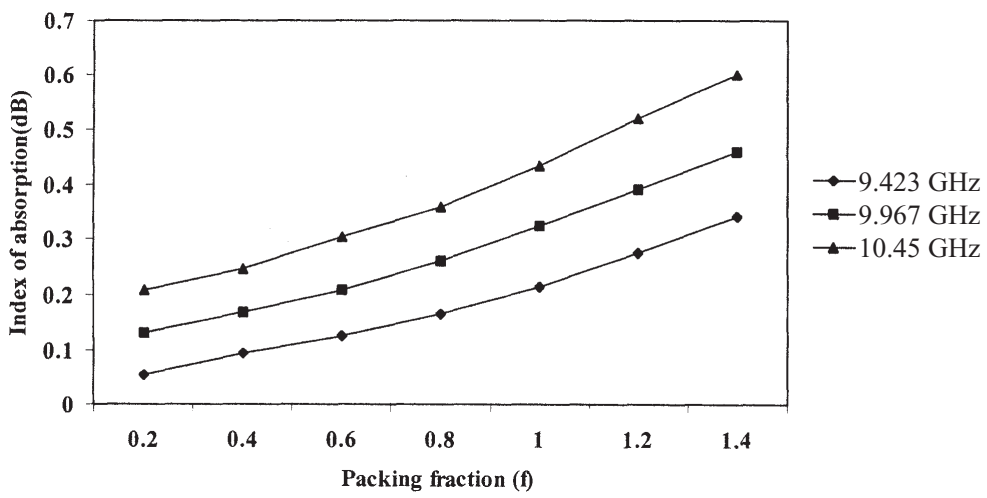

Figure 3. Variation of index of absorption with packing fraction $(f)$ for powder samples at different frequencies $(9.423,9.967$ and $10.45 \mathrm{GHz})$. 


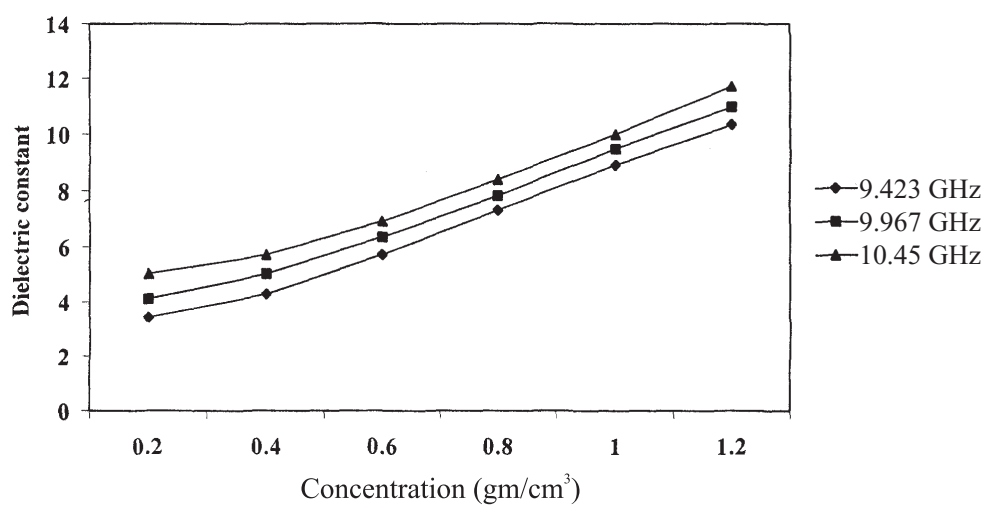

Figure 4. Variation of dielectric constant with concentration of powdered ore sample at different frequencies $(9.423,9.967$ and $10.45 \mathrm{GHz})$.

Figure 4 shows the variation of dielectric constant with concentration of the sample. It is found that dielectric constants increase with increasing concentration of powder ore sample. Dielectric constant also increases with frequency, because higher values of concentration give rise to inter-particle hindrance to dipolar motion giving rise to higher values of dielectric constant (Yadav \& Gandhi 1992).

\section{Conclusion}

From the above discussion, it may be concluded that the values of $\varepsilon^{\prime}, \varepsilon^{\prime \prime}$ and $(\tau)$ for all the ore samples increase systematically with increasing percentage of $\mathrm{Al}_{2} \mathrm{O}_{3}$ in bauxite. Higher percentages of conducting materials should cause more absorption of electromagnetic energy resulting in dampening of the dipolar motion. It is also possible to make measurements on samples prepared in the lab using different metals and different concentrations to obtain results, which might be useful in recommending the feasibility of processing a particular ore of a metal. The microwave technique described here is very convenient, accurate and straightforward, and thus can be used for different types of powders. Electrical transport behaviour of materials differing widely in characteristics can be studied by this method.

\section{References}

Altshuler H M 1981 Dielectric constant. Hand book of microwave measurements (eds) M Suchler, J Fox (New York: John Wiley) chap. 9, pp 511

Dube D C 1984 Determination dielectric parameter of thin films at microwave frequencies. Bull. Mater. Sci. 6: 1075-1086

Gandhi J M, Bhatnagar N, Yadav J S 1993 Estimation of metal in its ores through dielectric measurements at microwave frequencies. 4th Int. Symp. on Recent Advances in Microwave Technology, (New Delhi: Allied Publishers)

Vol Hippel A R 1961 Dielectric materials and waves (New York: John Wiley \& Sons) p. 28

Yadav J S, Gandhi J M 1992 Simple microwave technique for measuring the dielectric parameters of solids and their powders. Indian J. Pure Appl. Phys. 30: 427-431 